\title{
Prevalence and characterization of supplement use among healthy children and adolescents in an urban Japanese city
}

\author{
Nagisa Mori, Masaru Kubota*, Shoko Hamada, Ayako Nagai
}

Department of Human Life and Environment, Nara Women's University, Nara, Japan;

*Corresponding Author: masaru_kubota@chime.ocn.ne.jp

Received 2 January 2011; revised 20 February 2011, accepted 28 February 2011.

\section{ABSTRACT}

Although there are numerous studies on the use of supplements in children and adolescents from western countries, only a small number of studies have been conducted in Asian countries. This study was planned to determine the use of supplements and their association with lifestyles in healthy Japanese children and adolescents. This is a community-based cross-sectional study conducted in a Japanese urban city, Nara, in 2008. A total of 681 children and adolescents aged between 3 and 17 years were enrolled. The parents were asked to complete a questionnaire on the use of supplements among their children. Demographic information, health and nutrition status of children as perceived by parents, sleep duration, and a family history of supplement use were also collected. A total of $20.4 \%$ of children and adolescents are presently using (in the past one month) or have used (in the past one year excluding the past one month) supplements. The types of supplements most commonly used were minerals, followed by vitamins and blueberry extracts. Univariate analysis indicated that supplement use was associated with older age, poor perception of health status, shorter sleep duration, and a positive family history of supplement use. Multiple logistic regression analysis showed that age and a positive family history affected supplement use. Given the approximately $20 \%$ of prevalence of supplement use in Japanese children and adolescents, there is a need for further research to examine the supplements' effectiveness and safety.

Keywords: Supplement; Child; Adolescence; Japan; Lifestyle

\section{INTRODUCTION}

The use of supplements is expanding rapidly because of a growing worldwide awareness of health promotion [1]. The actual prevalence of supplement use differs greatly from country to country, presumably due to the diversity of cultural, nutritional, and economic conditions. A series of nationwide surveys in the United States indicated that the rates of supplement use in adults aged 18 years or older ranged from 32 to 52\% [2-5]. In European $[6,7]$ and Asian $[8,9]$ countries, the reported rates were lower, i.e. approximately between 15 and $30 \%$. These reports have also identified the characteristics of supplement users from cultural, economic, and nutritional points of view. In contrast, little is known about the prevalence of supplement use in children and adolescents except in the United States, where as high as approximately $30-50 \%$ of children and adolescents have been reported to use supplements [10-13]. Small cohort studies from Europe showed that the frequencies of supplement use were $25.8 \%$ for German children and adolescents [14], and $37-50 \%$ for Finnish children aged 2 and 3 years [15]. The only comprehensive report on supplement use in children in Asian countries, as far as we know, was the investigation carried out by the National Institute of Health and Nutrition in Japan, which found that $15 \%$ of preschool children used supplements [16]. However, this survey only targeted preschool children. Therefore, the purpose of the present study is to determine the prevalence of supplement use in healthy Japanese children and adolescents, and to consider the relationships between supplement use and demographic and lifestyle factors.

\section{MATERIALS AND METHODS}

\subsection{Study Design and Subjects}

This study was done in Nara city from April to May in 2008. Nara is an urban city in Japan with a population of 
approximately 370,000. Among them, the approximate population of children and adolescents aged between 3 and 17 years was 45,000 . The request for participation in the present study was first sent to several kindergartens or schools nearby. After obtaining consent by the principal, enrolled kindergartens or schools were decided by random selection. The questionnaire that we devised for the present study was distributed to the parents of the participants through their kindergartens or schools. The parents were then asked to complete the questionnaire at home. A "supplement" was defined as a preparation that provides various kinds of food substances in the form of either tablet, capsule, powder, liquid or jelly [17]. 975 questionnaires were distributed, and responses were obtained from 736 parents (recovery rate: 75.5\%). After responses with incomplete answers or those involving reported supplements that did not meet the definition given above, such as the over-the-counter medicines, were excluded, a total of 681 children and adolescents aged between 3 and 17 years were available for analysis. These included 142 preschool children (3-6 years), 125 students in the $4^{\text {th }}$ grade (9-10 years) and 109 students in the $6^{\text {th }}$ grade of elementary school (11-12 years), and 180 students in the $3^{\text {rd }}$ grade (14-15 years), and 125 in the $2^{\text {nd }}$ grade of senior high school (16-17 years). There were 326 males and 355 females. We obtained consent from all parents beforehand to use their children's data in our study. This project was approved by the ethical and epidemiological committee at Nara Women's University.

\subsection{Questionnaire}

First, it was asked whether the child was given any type of supplement in the past one month (present use) or the past one year excluding the past one month (past use). Also, data on types of used supplements, and the family history of supplement use were collected. Demographic features, parents' perceptions of children's health status and balance of diet, and average sleep hours per day in the past one month were requested.

\subsection{Statistics}

Difference in supplement use according to age was examined by one-way analysis of variance (ANOVA). After the present and past users were combined into total users, the association of supplement use with demographic features and various lifestyle elements was evaluated; the chi-square test was used to determine associations with sex and family history, and the KruskalWallis test was used for age, health status, balance of diet, and sleep hours. Multiple logistic regression analysis for prediction of children's supplement use was performed by including variables of age, gender, health status, food status, sleep hours, and family history of supplement use. In the analysis, age and sleep hours were categorized as indicated in Table 2. A statistical analysis was made using "StatMate III" (ATMS, Tokyo, Japan). $\mathrm{P}$ values less than 0.05 were considered significant.

\section{RESULTS}

\subsection{Supplement Use}

Table 1 indicates the numbers of samples and supplement users in relation to the age of the participants. A total of 139 children $(20.4 \%)$ had experience using supplements, including $72(10.6 \%)$ present users, and 67 $(9.8 \%)$ past users. In addition, the prevalence of total users tended to increase with an increase of age ( $\mathrm{p}<$ $0.001)$. There was no gender difference between supplement users and non-users.

\subsection{Association of Supplement Use with Demographic Features and Lifestyles}

Univariate analysis indicated that supplement use was associated with age, health status, sleep duration, and family history. However, multiple logistic regression analysis revealed that only age and family history of supplement use were associated with supplement use (Table 2).

\subsection{Types of Used Supplements}

The types of supplement most frequently used were minerals including iron, calcium, and zinc 54 (37\%), followed by vitamins including multi-vitamins, vitamin B and vitamin C 42 (29\%), and blueberry extracts 23 (16\%) (Figure 1). As far as side effects were concerned, only one case with a rash after receiving blueberry extracts was reported.

Table 1. Numbers of subjects and supplement users.

\begin{tabular}{lcccc}
\hline & $\begin{array}{c}\text { Total } \\
\text { number }\end{array}$ & & $\begin{array}{c}\text { Supplement } \\
\text { user }\end{array}$ & \\
\hline Age & & Present & Past & Total \\
$4-6 \mathrm{yr}$ & 142 & $4(2.8 \%)$ & $7(4.9 \%)$ & $11(7.7 \%)$ \\
$9-10 \mathrm{yr}$ & 125 & $7(5.6 \%)$ & $10(8.0 \%)$ & $17(13.6 \%)$ \\
$11-12 \mathrm{yr}$ & 109 & $16(14.7 \%)$ & $4(3.7 \%)$ & $20(18.3 \%)$ \\
$14-15 \mathrm{yr}$ & 180 & $27(15.0 \%)$ & $32(17.8 \%)$ & $59(32.8 \%)$ \\
$16-17 \mathrm{yr}$ & 125 & $18(14.4 \%)$ & $14(11.2 \%)$ & $32(25.6 \%)$ \\
Total & 681 & $72(10.6 \%)$ & $67(9.8 \%)$ & $139(20.4 \%)$ \\
\hline
\end{tabular}


Table 2. Association between supplement use and demographic or lifestyle factors.

\begin{tabular}{|c|c|c|c|c|c|c|}
\hline & & Supplemen & & & & \\
\hline & Number & $(-)$ & $(+)$ & $\mathrm{p}$ value & $\beta$ coeffieint $[95 \% \mathrm{CI}] \#$ & $\mathrm{p}$ value \\
\hline Total number (\%) & 681 & $542(79.6)$ & $139(20.4)$ & & & \\
\hline Gender & & & & 0.78 & $0.29[-0.12 \sim 0.72]$ & 0.17 \\
\hline Male & $326(47.9) \S$ & $258(47.6)$ & $68(48.9)$ & & & \\
\hline Female & $355(52.1)$ & $284(52.4)$ & $71(51.1)$ & & & \\
\hline Age & & & & $<0.001^{*}$ & $0.11[0.03 \sim 0.19]$ & $<0.01$ \\
\hline $3-6 \mathrm{yr}$ & $141(20.7)$ & $133(24.5)$ & $8(5.8)$ & & & \\
\hline $9-10 \mathrm{yr}$ & $125(18.4)$ & $108(19.9)$ & $17(12.2)$ & & & \\
\hline $11-12 \mathrm{yr}$ & $109(16.0)$ & $88(16.2)$ & $21(15.1)$ & & & \\
\hline $14-15 \mathrm{yr}$ & $180(26.4)$ & $121(22.3)$ & $59(42.4)$ & & & \\
\hline $16-17 \mathrm{yr}$ & $126(18.5)$ & $92(17.1)$ & $34(24.5)$ & & & \\
\hline Health status & & & & $<0.01 * *$ & $0.15[-0.21 \sim 0.52]$ & 0.41 \\
\hline Good & $485(71.2)$ & $401(74.0)$ & $84(60.4)$ & & & \\
\hline Moderate & $169(24.8)$ & $119(21.9)$ & $50(36.0)$ & & & \\
\hline Poor & $27(4.0)$ & $22(4.1)$ & $5(3.6)$ & & & \\
\hline Sleep duration & & & & $<0.001 * *$ & $0.28[-0.61 \sim 0.04]$ & 0.08 \\
\hline$<6 \mathrm{hrs} /$ day & $46(6.8)$ & $29(5.4)$ & $17(12.2)$ & & & \\
\hline 6 to $<7 \mathrm{hrs} /$ day & $216(31.7)$ & $154(28.4)$ & $62(44.6)$ & & & \\
\hline 7 to $<8 \mathrm{hrs} /$ day & $185(27.2)$ & $148(27.3)$ & $37(26.6)$ & & & \\
\hline $8 \mathrm{hrs} /$ day $\leq$ & $234(34.3)$ & $211(38.9)$ & $23(16.6)$ & & & \\
\hline Balance of diet & & & & 0.11 & $0.35[-0.03 \sim 0.72]$ & 0.07 \\
\hline Good & $334(49.0)$ & $275(50.7)$ & $59(42.4)$ & & & \\
\hline Moderate & $325(47.7)$ & 249 (45.9) & $76(54.7)$ & & & \\
\hline Poor & $22(3.3)$ & $18(3.4)$ & $4(2.9)$ & & & \\
\hline Family history of supplement use & & & & $<0.001 * *$ & $1.94[1.46 \sim 2.42]$ & $<0.001$ \\
\hline Negative & $351(51.5)$ & $326(60.1)$ & $25(18.0)$ & & & \\
\hline Positive & $330(48.5)$ & $216(39.9)$ & $114(82.0)$ & & & \\
\hline
\end{tabular}

$\S$ Numbers in parentheses indicate percentages. ${ }^{*}$ Chi-square test. $* *$ Kruskal-Wallis test. \# Logistic analysis.

\section{DISCUSSION}

Complementary and alternative medicine has become popular throughout developed countries as the public's health awareness has increased [18]. Supplements belonging to the category of functional foods play a central role in alternative and complementary medicine $[18,19]$. Although functional foods or supplements have not been fully defined, these compounds are thought to beneficially affect various functions in the body and to bring about an improvement of health or well-being [19]. Therefore, the purposes of their use are twofold: 1) the promotion or maintenance of health status, and 2) the treatment of certain disorders related to shortages of specific nutrients, especially in developing countries.

There have been numerous studies on the prevalence of supplement use in healthy adult populations. The results of surveys differ depending upon the definition of supplements, time of studies, and methods of surveys. In addition, the regulation of health claims by official 


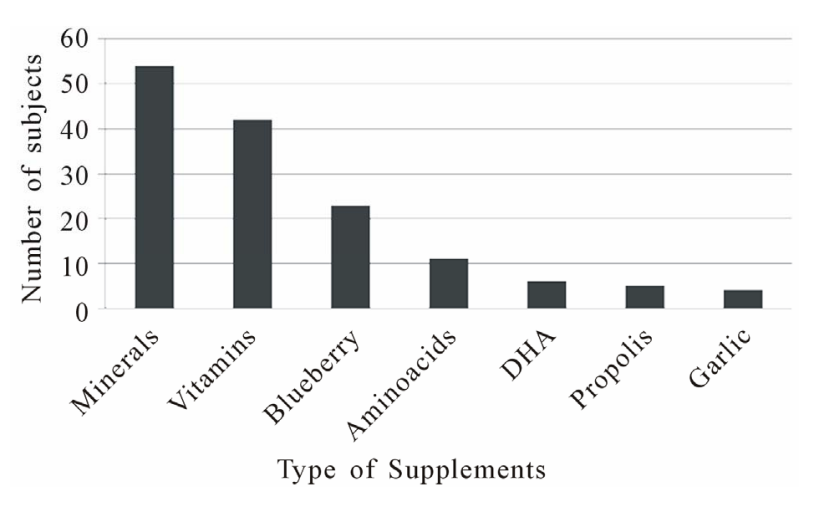

Figure 1. Types of supplements used in the present study. Multiple answers were allowed. Bars indicate the total number of each supplement users. Minerals included multi-minerals, calcium, iron and zinc. Vitamins included multi-vitamins, vitamin A, vitamin D, and ascorbic acid.

organization should be taken into consideration. In Japan, for example, supplement-type foods are not allowed to present health claims except "food with nutrient function claims". In the United States, however, health claims are well regulated by the Food and Drug Administration through provisions of the Food, Drug, and Cosmetic Act. Such difference may have an effect on the attitude of supplement consumers [20]. In the United States, a series of National Health and Nutrition Examination Survey (NHANES) demonstrated that the prevalence of supplement use in adults in the past two decades has ranged from 32.4 to $52 \%[2,4,5]$. There is a slight increasing trend with time. In these reports, supplement use was mainly investigated in adults aged 18 years and over during the past one month. Surveys from other countries have reported lower prevalence: $22 \%$ for men and 33\% for women in Sweden [7], 11\% for men and $16.4 \%$ for women in Japan [8], and $21.8 \%$ for men and $32 \%$ for women in Korea [9]. Notably, these reports involved older populations or different observation periods. In spite of the difference in prevalence found among the surveys, these surveys have postulated that similar demographic or lifestyle factors can be used for predicting supplement use. Female gender, older age, higher education, higher income, and good self-reported health were found to be associated with higher use of supplements [2-9]. Association of positive lifestyle factors with supplement use is regarded to reflect the characteristics of supplement users [21].

An earlier study by Kovar in 1981 demonstrated that $36 \%$ of children aged less than 18 years used vitamin or mineral supplements within the past two weeks [22]. Subsequent studies in the United States involving subjects of almost the same age group have shown similar prevalence rates of $31.8-34 \%[12,13]$. These values were not very different from those of European reports $[14,15]$. In a recent Japanese study targeting preschool children, the rate of supplement use was $15 \%$ [16]. Demographic or lifestyle factors associated with supplement use in children were consistent with those in adults. However, no gender difference was found in most studies [12, 14-16]. In addition, a positive family history of supplement use, especially supplement use by the mother, had an influence on children's use [10,16,23].

Our study is, as far as we know, the first cross- sectional study involving children aged 3-17 years in an Asian country. The overall prevalence of supplement use was $20.4 \%$ which was slightly higher than that found in the report by Sato et al. [16]. The difference is presumably due to the age of the subjects. Older age and a positive family history were associated with higher supplement use. Notably, a good lifestyle and a balanced diet, even if these were determined only according to the parent's perception, were found to be not associated with supplement use. Types of supplements commonly used in this study were minerals and vitamins. This finding is consistent with previous studies in children and adolescents [10-16]. Third-ranked supplement, blueberry extracts, is thought to be specific to Japan. The reason for its wide use is presumably the expectation that it has an effect on visual acuity as advertised through mass media [24], since the percentage of myopia in students is high in Japan [25]. Concerning adverse effects, Timbo et al reported that $4 \%$ of supplement users experienced adverse effects [26], but only one case was reported in this study.

There are several weaknesses in the present study. First, generalization of our results as the representative of children and adolescents in Japan should be careful because of the limited number of subjects. Second, the parent's ability to accurately differentiate various supplements was quite uncertain. In order to minimize this problem, a direct interview method should be introduced. Finally, important information about home income and parent's education level was not included. We omitted such questions because we were afraid that including them would cause a decrease in the response rate [16]. In spite of these weaknesses, we believe our present study to be important for understanding the present status of supplement use in children and adolescents, and in establishing future plans of supplement use. Majority of supplement users expect to receive adequate information about the supplements they are using, expect the participation of the authorities and the safety of supplement [27]. For these purposes, the future involvement of professionals such as doctors, dietitians, co-medical staffs, nutrition representatives as advisers of supplement use is necessary. 


\section{REFERENCES}

[1] Greger, J.L. (2001) Dietary supplement use: Consumer characteristics and interests. Journal of Nutrition, 131, 1339S-1343S.

[2] Koplan, J.P., Annest, J.L., Layde, P.M. and Rubin, G.L. (1986) Nutrient intake and supplementation in the United States (NHANES II). American Journal of Public Health, 76, 287-289. doi:10.2105/AJPH.76.3.287

[3] Lyle, B.J., Mares-Perlman, J.A., Klein, B.E.K., Klein, R. and Greger, J.L. (1998) Supplement users differ from nonusers in demographic, lifestyle, dietary and health characteristics. Journal of Nutrition, 128, 2355-2362.

[4] Balluz, L.S., Kieszak, S.M., Philen, R.M. and Mulinare, J. (2000) Vitamin and mineral supplement use in the United States. Results from the third National Health and Nutrition Examination Survey. Archives of Family Medicine, 9, 258-262. doi:10.1001/archfami.9.3.258

[5] Radimer, K., Bindewald, B., Hughes, J., Ervin, B., Swanson, C. and Picciano, M.F. (2004) Dietary supplement use by US adults: Data from the National Health and Nutrition Examination Survey, 1999-2000. American Journal of Epidemiology, 160, 339-349.

doi:10.1093/aje/kwh207

[6] Bates, C.J. (2000) Dietary supplement use at the population level: recent experience from 1994-5 British national diet and nutrition survey: People aged 65 years and over. The Journal of Nutrition, Health \& Aging, 4, 51-53.

[7] Messerer, M., Johansson, S.E. and Wolk, A. (2001) Sociodemographic and health behavior factors among dietary supplement and natural remedy users. European Journal of Clinical Nutrition, 55, 1104-1110. doi:10.1038/sj.ejen. 1601272

[8] Ishihara, J., Sobue, T., Yamamoto, S., Sasaki, S. and Tsugane, S. (2003) Demographics, lifestyles, health characteristics, and dietary intake among dietary supplement users in Japan. International Journal of Epidemiology, 32, 546-553. doi:10.1093/ije/dyg091

[9] Lee, J.S. and Kim, J. (2009) Factors affecting the use of dietary supplement by Korean adults: Data from Korean national health and nutrition examination survey III. Journal of the American Dietetic Association, 109, 15991605. doi:10.1016/j.jada.2009.06.374

[10] Yu, S.M., Kogan, M.D. and Gergen, P. (1997) Vitamin-mineral supplement use among preschool children in the United States. Pediatrics, 100, 4-11. doi:10.1542/peds.100.5.e4

[11] Gilmore, J.M.E., Hong, L., Broffitt, B. and Levy, S.M. (2005) Longitudinal patterns of vitamin and mineral supplement use in young white children. Journal of the American Dietetic Association, 105, 763-772. doi:10.1016/j.jada.2005.02.011

[12] Picciano, M.F., Dwyer, J.T., Radimer, K.L., Wilson, D.H., Fisher, K.D., Thomas, P.R., Yetley, E.A., Moshfegh, A.J., Levy, P.S., Nielsen, S.J. and Marriott, B.M. (2007) Dietary supplement use among infants, children, and adolescents in the United States, 1999-2002. Archives of Pediatrics \& Adolescent Medicine, 161, 978-985. doi:10.1001/archpedi.161.10.978

[13] Shaikh, U., Byrd, R.S. and Auinger, P. (2009) Vitamin and mineral supplement use by children and adolescents in the 1999-2004 national health and nutrition examination survey: Relationship with nutrition, food security, physical activity, and health care access. Archives of Pediatrics \& Adolescent Medicine, 163, 150-157. doi:10.1001/archpediatrics.2008.523

[14] Sichert-Hellert, W. and Kersting, M. (2004) Vitamin and mineral supplement use in German children and adolescents between 1986 and 2003: Results of the DONALD study. Annals of Nutrition \& Metabolism, 48, 414-419. doi:10.1159/000083574

[15] Marjamaki, L., Rasanen, M., Uusitalo, L., Ahonen, S., Veijola, R., Knip, M. and Virtanen, S.M. (2004) Use of vitamin $\mathrm{D}$ and other dietary supplements by Finnish children at the age of 2 and 3 years. International Journal for Vitamin \& Nutrition Research, 74, 27-34. doi:10.1024/0300-9831.74.1.27

[16] Sato, Y., Yamagishi, A., Hashimoto, Y., Virgona, N., Hoshiyama, Y. and Umegaki, K. (2009) Use of dietary supplements among preschool children in Japan. Journal of Nutritional Science and Vitaminology, 55, 317-325. doi:10.3177/jnsv.55.317

[17] Shi, H.J., Nakamura, K., Shimbo, M. and Takano, T. (2005) Dietary supplement consumption among urban adults influenced by psychological stress: its pronounced influence upon persons with a less healthy lifestyle. British Journal of Nutrition, 94, 407-414. doi:10.1079/BJN20051494

[18] Eisenburg, D.M., Davis, R.B., Ettner, S.L., Appel, S., Wilkey, S., Rompay, M.V. and Kessler, R.C. (1998) Trends in alternative medicine use in the United States, 1990-1997: results of a follow-up national survey. JAMA, 280, 1569-1575. doi:10.1001/jama.280.18.1569

[19] Mullie, P., Guelinckx, I., Clarys, P., Degrave, E., Holens, M. and Vansant, G. (2009) Cultural, socioeconomic and nutritional determinants of functional food consumption patterns. European Journal of Clinical Nutrition, 63, 12901296. doi:10.1038/ejen.2009.89

[20] Hathcock, J. (2001) Dietary supplements: How they are used and regulated. Journal of Nutrition, 311, 1114S$1117 \mathrm{~S}$.

[21] Bender, M.M., Levy, A.S., Schucker, R.E. and Yetley, E.A. (1992) Trends in prevalence and magnitude of vitamin and mineral supplement usage and correlation with health status. Journal of the American Dietetic Association, 92, 1096-1101.

[22] Kovar, M.G. (1985) Use of medications and vitamin-mineral supplements by children and youths. Public Health Reports, 100, 470-473.

[23] Lee, Y., Mitchell, D.C., Smiciklas-Wright, H. and Birch, L.L. (2002) Maternal influences on 5- to 7-year-old girls' intake multivitamin-mineral supplements. Pediatrics, 109, 46-52. doi:10.1542/peds.109.3.e46

[24] Johnson, E.J. (2002) The role of carotenoids in human health. Nutrition in Clinical Care, 5, 56-65. doi:10.1046/j.1523-5408.2002.00004.x

[25] Matsumura, H. and Hirai, H. (1999) Prevalence of myopia and refractive changes in students from 3 to 17 years of age. Survey of Ophthalmology, 44, S109-115. doi:10.1016/S0039-6257(99)00094-6

[26] Timbo, B.B., Ross, M.P., McCarthy, P.V. and Lin, C.T. (2006) Dietary supplements in a national survey: Prevalence of use and reports of adverse events. Journal of the 
American Dietetic Association, 106, 1966-1974. doi:10.1016/j.jada.2006.09.002

[27] Blendon, R.J., DesRoches, C.M., Benson, J.M., Brodie, M. and Altman, D.E. (2001) "Americans' views on the use and regulation of dietary supplements. Archives of Internal Medicine, 161, 805-810.

doi:10.1001/archinte.161.6.805 